\title{
Mídia e religião: estratégias de "cura" financeira pela IURD
}

\author{
Carlos Renan Samuel Sanchotene / Viviane Borelli
}

\section{Resumo:}

O presente artigo faz uma reflexão sobre o processo de midiatização do campo religioso e as estratégias de captura dos fiéis, a partir do programa televisivo religioso «A hora dos empresários», da Igreja Universal do Reino de Deus (IURD). Transmitido pela Rede Record de Televisão, o programa é destinado às pessoas que buscam uma solução para a crise financeira. Com estratégias distintas, os pastores oferecem ajuda aos telespectadores por meio dos serviços de auto-referencialidade do próprio discurso religioso. O estudo evidencia que a "cura" financeira, as conquistas e vitórias só podem ser alcançadas dentro do templo.

\section{Palavras Chave:}

midiatização; religião; televisão; Igreja Universal do Reino de Deus

\begin{abstract}
:
The present article makes a reflection about the process of mediatization of religious subject and the strategies of capture from the churchgoers, based on televisive program religious «A hora dos empresários», from Igreja Universal do Reino de Deus (IURD). Broadcasted by Rede Record de Televisão, the program is directed to people who need a solution financial crisis. With different strategies, the pastors offer helps to television viewers through the service of self allusion of the proper speech religious. The study evidences that the financial cure, the conquest and victories only can be ranging inside of the temple.
\end{abstract}

\section{Keywords:}

mediatization; religion; television; Igreja Universal do Reino de Deus

A problemática acerca das relações entre mídia e religião insere-se num quadro complexo em que os processos simbólicos engendrados via televisão sinalizam uma atividade específica desenvolvida pelo campo religioso a partir de estratégias singulares de captura dos fiéis. Essas atividades demandam ofertas discursivas elaboradas através de processos de midiatização que garantam visibilidade ao campo religioso e, ao mesmo tempo, permanência junto aos fiéis.

Através de operações enunciativas, o dispositivo televisivo constrói um outro conceito de religião que não se concretiza mais só no âmbito institucional da Igreja, mas na esfera midiática. Nesse contexto e, em função da modernidade, os públicos encontram-se espalhados territorialmente (BAUMAN, 2001) e, através do funcionamento dos dispositivos midiáticos, a sociedade vive um momento caracterizado por novos modos de vivenciar, praticar e manifestar suas religiosidades.

A emergência neodevocional religiosa constrói novas comunidades midiáticas que se unem diante da tela da televisão fazendo desse ambiente um espaço para buscar soluções de problemas familiares, de saúde, relacionamentos e financeiros. Da mesma forma, essa nova comunidade que se forma, urge de um momento em que a sociedade enfrenta mudanças de ordem cultural massiva para a midiática. "Chama-se atenção para as estratégias pelas quais as instituições religiosas, via-mídia, se enlaçam numa determinada estrutura 
simbólica voltada para instituir novos laços com a esfera dos fiéis” (FAUSTO NETO, 2004: 178).

Nesse sentido, o presente artigo busca discutir essas relações entre o campo midiático e o religioso, bem como a questão da midiatização da religião, a partir de um caso específico, o programa «A hora dos empresários», destinado a pessoas que estão em dificuldades financeiras, da Igreja Universal do Reino de Deus (IURD), transmitido pela Rede Record de Televisão.

\section{Mídia e religião}

Os campos midiático e religioso se constituem e interagem co-determinando relações entre campos sociais, caracterizados como instituições dotadas de legitimidade e certa autonomia com os demais campos. Na esfera do discurso religioso, o campo da mídia atua com caráter de superintendência, já que a partir de sua legitimidade garante visibilidade aos anseios dos demais campos.

Segundo Rodrigues (1999) cada campo é uma instituição singular, legitimada, reconhecida e respeitada pelo conjunto da sociedade. O campo midiático é aquele que promove o diálogo e a discussão entre os demais campos que utilizam a mídia para ganhar visibilidade na esfera pública. No âmbito religioso, a mídia acaba por modificar estruturalmente as articulações dessa instituição, devido aos seus próprios modos de operar que acaba interferindo no processo discursivo, pois precisa se adequar às lógicas midiáticas.

A alta visibilidade que o campo midiático garante ao religioso ocorre através de tensões. Em uma organização social complexa, os campos interagem em um sistema de intensa atividade social desenvolvendo suas funções de acordo com suas simbólicas. E, o campo das mídias, como afirma Esteves (1998), possui na discursividade sua maior simbólica garantindo o que chama de "mediação social generalizada", preservando certa homogeneidade social.

A competência do campo das mídias está, justamente, na especificidade de sua discursivação na esfera púbica e envolvida sob tensões com outros campos dentro de uma ambiência conflituosa. A partir de sua legitimidade, o campo religioso vislumbra para o poder de sua simbólica planejando estratégias de intervenção e apropriação desse campo centralizante nas mediações simbólicas de caráter social homogêneo.

Dentro dessa lógica, observa-se cada vez mais, o uso estratégico da mídia por parte dos neopentecostais. Tomando como referência a IURD destacam-se os veículos midiáticos de sua propriedade. No ano de 2002, era proprietária de 62 emissoras de rádio, da terceira maior empresa de televisão brasileira, a Rede Record (que reúne 63 emissoras afiliadas), além da Rede Mulher, Rede Família e CNT. A igreja também dispõe do portal Arca Universal (www.arcauniversal.com.br), que oferece ao internauta links relacionados a produtos e mídias da IURD, além de seu site institucional (www.igrejauniversal.org.br).

Em relação aos campos, Bourdieu (1989) os compreende como um espaço estruturado de posições sociais que possui uma lógica singular onde determinados «habitus» se fazem presentes, de atuação dos indivíduos que tem a finalidade de ocupar determinadas posições a partir de interesses próprios.

Com especificidades próprias, cada campo é carregado de embates e diálogos movido por movimentos que residem na própria luta que reproduz estruturas e hierarquias a partir das composições constitutivas do campo. O campo circula nas ações e reações dos agentes que "não têm outra escolha a não ser lutar para manterem ou melhorarem a sua posição no campo, quer dizer, para conservarem ou aumentarem o capital específico que só 
no campo se gera" (BOURDIEU, 1989: 47). Com isso, as relações entre os campos são de poder, um dos aspectos básicos do campo das mídias que através do seu discurso estabelece uma zona de conflito e disputa em busca desse poder ou de sua manutenção.

\section{Midiatização da religião}

A organização de estratégias midiáticas é fundamental para que a religião realize táticas de contato com seu público, o que decorre a partir do complexo fenômeno da midiatização constituído por um processo em que os dispositivos midiáticos agem sobre práticas sociais dos outros campos, como o da religião, estruturando-as e engendrando-as por meio de operações tecno-simbólicas.

Os dispositivos tecno-simbólicos apreendem e capturam para si as gramáticas de outros campos e através de um complexo processo de produção constroem e estabelecem contratos de leitura (VERÓN, 2003). A comunicação midiática resulta da articulação entre dispositivos tecnológicos e as condições específicas de produção e recepção. Os dispositivos são os principais mecanismos de geração e de criação de novos símbolos para a religião. Segundo Verón (1997: 13), "um meio de comunicação social é um dispositivo tecnológico de produção-reprodução de mensagens associado a determinadas modalidades (ou práticas) de recepção de mensagens ditas". Como um suporte técnico, esse dispositivo engendra processos complexos e simbólicos de produção e recepção que configuram a estrutura do mercado discursivo.

Ainda de acordo com Verón (1997), a mídia ocupa um espaço central nas relações entre os campos sociais e os indivíduos. É ela quem promove conexões e por meio de suas operações acaba afetando os modos com que os campos e seus sujeitos relacionam-se. A centralidade da mídia representa que suas lógicas de funcionamento têm afetado os outros campos, havendo um cruzamento de interesses, negociações, disputas e inter-relações.

$\mathrm{Na}$ relação entre campos sociais, tomam-se como partida algumas reflexões que discutem a atuação da mídia e seus vínculos frente a uma sociedade que está, cada vez mais, sofrendo interferências dos meios de comunicação. Gomes (2006) trabalha a midiatização no âmbito de um processo social complexo engendrado por mecanismos de produção de sentido social. Para o autor, "a midiatização é a reconfiguração de uma ecologia comunicacional” (GOMES, 2006: 121). Ou seja, através desse processo é possível compreender o funcionamento da mídia e da sociedade que está, cada vez mais, se auto-percebendo a partir do fenômeno midiático.

Como um canal de socialização, o autor afirma que a TV aproxima e integra as pessoas em uma comunidade nacional e universal. De acordo com ele, as interpretações do mundo, muitas vezes, são feitas a partir de pontos de referência que os indivíduos tomam sob o que é midiatizado pelos meios de comunicação de massa, surgindo assim uma nova ambiência, um novo modo de ser no mundo configurado pela presença da mídia.

Nesse mesmo sentido, Sodré (2006: 23) pensa o fenômeno como um novo bios, de qualificação cultural própria, a chamada tecnocultura que "implica uma nova tecnologia perceptiva e mental, portanto, um novo tipo de relacionamento do indivíduo com as referências concretas e com a verdade (...)". É o que ele chama de escolha individualista, uma prática recorrente na sociedade moderna em relação a novos modos de pensar e agir, que parte dos desejos individuais, de qualificação existencial orientado pela mídia, a responsável pelos processos de interação social e construção social. 
A evolução dos meios massivos complexifica os modos e estratégias com que a mídia utiliza na captura e conquista de suas audiências. De acordo com Fausto Neto (2008), o que existe agora, é uma ambientação que funciona uma nova forma de sociedade impulsionada por mecanismos geradores de sentidos, cujas interações sociais são estabelecidas através de ligações sócio-técnicas. "A disseminação de novos protocolos técnicos em toda extensão da organização social, e de intensificação de processos que vão transformando tecnologias em meios de produção, circulação e recepção de discursos" (FAUSTO NETO, 2007: 92).

Através do atravessamento de dispositivos tecno-simbólicos, o movimento neopentecostal, em especial a IURD, constrói sentidos religiosos inserindo sua programação religiosa nos lares dos credos e não-credos, transformando o ambiente televisivo num espaço terapêutico, amenizando problemas e propondo soluções.

\section{A Rede Record e a Igreja Universal do Reino de Deus}

A Rede Record de Televisão foi fundada em 1953 pelo empresário Paulo Machado de Carvalho, tendo como principal concorrente, na época, a TV Tupi. Nas duas primeiras décadas, a programação era basicamente composta por programas de auditório, humor e musicais. Os festivais de música popular brasileira deram à emissora grande índices de audiência.

Em 1972, 50\% de suas ações são vendidas para o comunicador Silvio Santos. As transmissões são feitas principalmente por desenhos animados, séries e filmes. A emissora entra na década de 1980 com baixos indíces de audiência, operando em conjunto com a TVS, sendo praticamente uma retransmissora do SBT.

Em 1989, a emissora de Silvio Santos (sócio majoritário) e Paulo Machado de Carvalho (no momento havia se tornado o sócio minoritário) é vendida para a Igreja Universal do Reino de Deus, comandada pelo bispo Edir Macedo Bezerra. Em 1990, a Record apresentou seu novo «slogan» "de volta pro futuro", ampliando sua programação, mantendo o jornalismo como carro-chefe e iniciando a formação de uma rede nacional de emissoras.

Na década de 90, é desencadeada uma campanha contra a Rede Globo(1) que ataca a emissora do bispo Macedo através dos telejornais. A situação piora quando a Globo coloca no ar a minissérie «Decadência», de Dias Gomes, que tinha como trama central a história de um pastor que criou uma seita para tirar dinheiro de pessoas humildes e ingênuas. Edir Macedo acreditou ser um ataque pessoal e declarou que nos próximos dez anos a Record seria a rede com maior potencial para ameaçar à emissora de Roberto Marinho.

Na mesma década começa a expansão da emissora paulista, que tem sua sede principal localizada em São Paulo (SP). Em 1995, a Record investiu pesado em equipamentos(2) de última geração e mudou de sua antiga sede no bairro do Aeroporto, para uma nova instalação, na Barra Funda (atual sede). A partir daí, a emissora passou a contar com os equipamentos mais sofisticados da televisão brasileira. Com o apoio financeiro da Universal, a Record começou a comprar outras emissoras, expandindo ainda mais sua rede.

Atualmente, a emissora do bispo Macedo opera em canal aberto e é presidida por Alexandre Raposo. A cobertura atinge 99,01 \% do território brasileiro, além da América do Sul, América do Norte, África, Europa e parte da Ásia. No Brasil, conta com 14 emissoras próprias, uma emissora própria internacional (TV Miramar de Moçambique) e 101 emissoras afiliadas. No Rio Grande do Sul, a Record atua em Porto Alegre, Carazinho, Pelotas e Santa Maria. 
O lucro líquido da Record em 2007 foi de R\$ 83 milhões, resultado 60\% superior ao de 2006 (R\$ 52 milhões)(3).A emissora encerrou o primeiro bimestre de 2008 (janeiro/fevereiro) com um crescimento de $45 \%$ em relação ao mesmo período do ano passado. Em 2008, a Record pretende faturar cerca de R $\$ 1,8$ bilhão, 25\% a mais do que o faturamento de 2007. Parte dessa receita vem da Igreja Universal, que paga entre R \$ 300 milhões e R \$ 400 milhões anuais pelo espaço que ocupa nas madrugadas. Em 2007, a Record apresentou um crescimento de quase $40 \%$ na sua audiência. A programação da emissora que tem como «slogan» "A caminho da liderança" investe em jornalismo, dramaturgia e entretenimento.

A programação da IURD vai da $1 \mathrm{~h}$ da madrugada até às $7 \mathrm{~h}$ da manhã e das $13 \mathrm{~h}$ às $14 \mathrm{~h}$, de segunda à sextafeira, totalizando 7 horas de programação religiosa na Record. Aos sábados, a programação vai da $1 \mathrm{~h}$ às $8 \mathrm{~h}$ e das $8 \mathrm{~h}$ às $8 \mathrm{~h} 30$ vai ao ar «Bíblia em foco». Nos domingos, a IURD tem inserções da $1 \mathrm{~h}$ às $7 \mathrm{~h}$ da manhã; das $7 \mathrm{~h} 30$ às $8 \mathrm{~h}$ é apresentado o programa «Santo oculto em seu lar» e das $8 \mathrm{~h}$ às $9 \mathrm{~h}$ entra a programação da IURD. De segunda à sexta, a programação religiosa ocupa um espaço de 6 horas diárias, nos sábados e domingos são 7h30. Em um total de 168 horas de programação da Record durante a semana, o espaço religioso ocupa 50 horas, o equivalente a $29,7 \%$ da grade semanal.

A programação IURD não tem horários de programas definidos. A faixa horária do espaço comprado contém programas que vão ao ar em horários distintos durante a madrugada. Alguns programas são gravados, outros ao vivo. Entre eles, «Fala que eu te escuto», «Ponto de luz», «Ponto de fé», «SOS espiritual» e «SOS»programas de pregação, assim como todos produzidos pela IURD.

\section{«A hora dos empresários»}

O programa da IURD é veiculado pela Rede Record em horários alternados durante a madrugada. Foi analisada uma edição do programa, que foi ao ar em julho de 2008, feito pela igreja de Porto Alegre (RS) e transmitido para todo Estado. Com duração de 30 minutos, «A hora dos empresários» é apresentado pelo pastor João Marcos, que circula em pé pelo estúdio e pelo pastor Natanael, que fica sentado atrás de uma mesa de escritório.

«A hora dos empresários» pode ser caracterizado como "tele-escuta", pois os telespectadores participam, deixam seus nomes e expõem seus problemas de ordem financeiros. Geralmente são microempresários que se encontram endividados ou perderam tudo. Também há pessoas que estão atrás de um emprego, mas não encontram. A solução é única: ir até um templo mais próximo, sempre na segunda-feira, e participar do "Congresso Empresarial" que conta com a "Nação dos 318".

$\mathrm{Na}$ "Nação dos 318", um pastor lidera outros 318 que estão no altar frente aos fiéis, proferindo mensagens de salvação. Todas as sessões acontecem em horários diferenciados que vão desde as $7 \mathrm{~h}$ da manhã até às $22 \mathrm{~h}$. Os horários são pré-programados e acontecem em diversas cidades do Brasil. O telespectador é convidado a chegar um pouco mais cedo para receber uma "benção" especial, deixar seus pedidos através de uma folha de papel para que os pastores levem até o Rio Guaíba para fazerem uma oração, bem como ouvirem os depoimentos de pessoas que "venceram" na vida. 


\section{O convite para a "parceria"}

É interessante perceber que os problemas financeiros, de qualquer ordem, já não são mais solucionados com a força do trabalho individual. A solução está em uma força maior, cuja "cura" está dentro do templo, através da formação de uma sociedade divina composta pelo "Congresso Empresarial" que está unida em busca da salvação financeira.

Não importa a classe social, o nível de escolaridade ou o cargo ocupado pelo fiel. O que interessa é "crer" em Deus e buscar a igreja para juntos formar uma parceria que liberte da má situação:

O primeiro passo para qualquer pessoa vencer na vida é ela ser fiel a Deus. Além de você ser fiel a Deus tem que haver dentro de você um espírito de perseverança. Muitas pessoas têm vários diplomas, cursos superiores, enfim, a capacidade dela até excede, mas por que estão fracassando no mundo dos negócios? (...) Porque falta uma parceria com Deus. Sem a unção de Deus você não chega muito longe, meu amigo, minha amiga. Até porque está escrito na bíblia sagrada: sem mim nada podeis fazer. (...) Por mais que você esteja com todos os diplomas na mão, sem essa unção, essa parceria, isso é impossível (Pastor João Marcos).

\section{Enfrentando a "fila"}

Ao longo do programa, os pastores mostram que é possível aumentar o faturamento nos negócios em uma época de crise financeira, em um período de desemprego onde as pessoas fazem sacrifícios, enfrentam filas na busca por uma oportunidade. Os pastores também citam as filas de espera por um dinheiro, uma indenização ou uma causa que não sai na justiça.

No entanto, isso só é possível no “Congresso Empresarial”. É fundamental que o telespectador enfrente essas mesmas dificuldades se propondo a ir até um templo, pois quanto maior for essa dificuldade e a distância até a igreja, maior será a vitória.

Além disso, é mostrada uma fila de fiéis onde o pastor passa com um microfone perguntando se aumentou o faturamento. A confirmação é unânime. Ou seja, enquanto existem pessoas fechando as portas no negócio, passando dificuldades, no "Congresso" há pessoas abrindo negócios, ouvindo notícias boas, o que estimula o telespectador. Logo, pagar o dízimo é algo que vale a pena.

Quando uma pessoa se propõe a ficar numa fila de desempregados, primeiro ela tem que levantar muito cedo pra pegar um lugar na fila. Aí ela chega e fica horas, até a tarde e, às vezes, não é atendida. Quando é atendida não é chamada nunca. A pessoa faz todo um esforço. Por que não também fazer esse mesmo esforço pra vim participar do Congresso, para que haja uma mudança e que ela possa entrar na fila de quem está vencendo? (Pastor Natanael).

Quanto maior é a distância da sua casa até a Catedral, maior é a sua vitória. Porque se segunda-feira você chegar aqui e não tiver filas de depoimentos, você não precisa voltar nunca mais. É um desafio que eu estou lançando agora. Nós compramos a tua briga, só que você vai ter que se juntar a nós. É uma sociedade (Pastor João Marcos). 
Quantas pessoas estão nos acompanhando agora, estão na fila talvez da justiça esperando a causa sair, esperando o dinheiro sair, esperando alguma empresa chamar pra trabalhar. Só que aqui na catedral, segunda-feira, no Congresso Empresarial, nós temos fila de depoimentos. (...) Enquanto muita gente tem reclamado que não consegue vender nada. Veja o tamanho da fila. A palavra de Deus está se cumprindo na sua vida, aqui no Congresso (Pastor João Marcos).

\section{Fechando o "negócio"}

O pastor-apresentador ouve os telespectadores que entram ao vivo e oferece ajuda através de serviços de autoreferencialidade do próprio discurso religioso da IURD. No entanto, não basta apenas ouvir a palavra do pastor, é preciso participar das orações, ou seja, ir até a igreja presencialmente onde está o "milagre". Ao telespectador, são oferecidos diversos horários para que os mesmos procurem o templo, o que seria um primeiro passo para a salvação. Pelo telefone, os telespectadores expõem as suas situações, seus "dramas" e "desesperos".

A palavra de ordem dos pastores é a perseverança através da fé. Os pastores convocam os "necessitados" a participarem do "Congresso" na segunda-feira, dia que para eles, é onde tudo começa e as portas dos negócios se abrem. A atitude de sair de casa e ir até a igreja é fundamental para a cura dos problemas. $\mathrm{O}$ fato de se deslocarem é considerado por eles como um desafio inicial. E não importa a religião, pois o principal objetivo dos pastores é brigar pela "causa" dos fiéis, ajudando-os a superar as crises financeiras.

Não importa a sua religião, nós estamos unindo forças. Todo povo da Igreja Universal está convocado para estar segunda-feira no maior Congresso Empresarial. Você vai passar para nossas mãos o seu problema. Nós compramos a tua causa, nós brigamos pela sua empresa, nós brigamos pelo seu crescimento, nós brigamos pela sua empresa (Pastor João Marcos).

Então você tem um problema e quer sair dele, com certeza. E nós estamos aqui pra te ajudar. (...) Nós queremos pegar na sua mão pra tirar você do poço. Então o que você vai fazer, vai pegar uma folha de papel e escrever seus problemas. Nesta segunda-feira você vai trazer e entregar na nossa mão. (...) $\mathrm{Ou}$ seja, você vai sair dessa crise que está passando (Pastor Natanael).

Posso marcar com você também pra entrar nessa fila? Vamos abrir de novo o seu salão de beleza e a empresa do seu marido vai crescer por causa da sua fé. Faltou Deus. Seu marido não está buscando Deus. Na segunda-feira, começa você por ele e a mudança vai vim através de você (Pastor João Marcos).

A senhora pode nos procurar segunda-feira que horas? Quando acabar a reunião não vai embora, me procura pra eu te atender. Tá combinado amiga? Pode ser às $8 \mathrm{~h}$, pode ser $12 \mathrm{~h}$, pode ser $15 \mathrm{~h}$, mas desde que você venha. Tem que ser na Catedral que é só aqui que tem os 318 (Pastor Natanael).

\section{Em busca de uma "pesca" divina}


Às margens do rio Guaíba, em Porto Alegre, os pastores comprovam aos telespectadores e aos fiéis, que os pedidos escritos em uma folha de papel são realmente levados ao rio, onde é feita uma oração. Através de trechos bíblicos os pastores citam a passagem de Pedro, que obedeceu a palavra de Jesus e, ao lançar sua rede ao mar, conseguiu realizar uma pesca maravilhosa. O mesmo vai acontecer com os fiéis que forem até a igreja.

De acordo com os pastores, é no templo maior que existem especialistas para combater a miséria e o fato de estarem às margens do Guaíba dá credibilidade ao discurso da IURD, pois o rio simboliza a grandeza divina que envolve as maiores criações de Deus. Ou seja, o céu, a terra e o mar, simbolizados pelo Guaíba, representam que para Deus não há limites e os problemas financeiros de cada credo são pequenos diante das grandezas de Deus e das maravilhas que Ele pode fazer.

Através das mãos dos pastores, os pedidos dos fiéis serão atendidos, pois eles representam a força de Deus, junto com mais 318 "homens de Deus" que estão reunidos no templo em uma corrente de oração que tira os fiéis do desemprego e abrem as portas para o sucesso financeiro.

Para Deus não tem limites. Não importa o tamanho da dívida, da crise, da situação que esse empresário está de falência, já perdeu tudo, está desempregado. Deus é isso aqui, é infinito e se você colocar o seu problema nas mãos dele, Ele vai fazer com que você chegue a ser desse tamanho (Pastor Natanael).

Se Ele mediu a água do universo na concha de sua mão. Então ele está dizendo o seguinte: eu posso colocar tudo que é grande nas suas mãos, através da fé, porque nós estamos diante das três grandezas de Deus, o céu, a terra e o mar (Pastor João Marcos).

E nós pedimos a você que quer ver a grandeza desse Deus na sua vida, pra você trazer nessa segundafeira, no Congresso Empresarial, os seus pedidos, onde nós iremos trazer aqui para aclamar por você diante das três maiores grandezas de Deus. (...) Você que quer ver a grandeza desse Deus na sua vida, traga nessa segunda-feira o seu pedido, entrega nas nossas mãos para que aqui no Guaíba possamos aclamar por você (Pastor João Marcos).

\section{“Aqui no Congresso tem gente abrindo negócios"}

Para comprovar os "milagres" realizados por Deus através do "Congresso Empresarial", uma demonstração é feita através do depoimento de fiéis. São filas de pessoas que se formam no corredor do templo onde o pastor passa por cada um questionando a sua atual situação financeira.

Prosperidade, viagens, empresa, reconhecimento profissional, sucesso, abundância, carros, imóveis, conquistas e estabilidade são os efeitos causados na vida daqueles que procuram o "Congresso". Os depoimentos são uma forma de concretizar o discurso dos pastores que questionam os fiéis sobre seu passado e o seu presente.

A situação financeira do passado aproxima-se com a atual situação dos telespectadores que telefonam em 
busca de ajuda. O atual estágio fincanceiro de quem participa do "Congresso" é um fator que estimula os telespectadores a bucarem uma "solução" para sua crise. O discurso da IURD é de que a "cura" financeira só pode ser encontrada através da atitude de ir até o templo, pois cada ação produz uma reação, um resultado de prosperidade e riqueza.

Enquanto muita gente tem reclamado que não consegue vender nada. Veja o tamanho da fila. A palavra de Deus está se cumprindo na sua vida, aqui no Congresso. Enquanto tem gente fechando lojas, portas, aqui no Congresso tem gente abrindo negócios (Pastor João Marcos).

Deus deu uma direção pra eu abrir uma empresa. Além do ramo que eu já trabalhava com publicidade, Deus deu uma outra direção e Deus começou a abençoar. Eu comprei minha casa, conquistei um carro, então hoje eu posso sair com a minha esposa, levar no melhor restaurante (Depoimento 1).

Foi feita uma auditoria, uma perícia e foi contatada que eu nada devia. Na igreja eu vim um ano, todos os dias com chuva, frio, o que tivesse eu vinha e ali Deus começou a me prosperar, abençoar. Eu tenho uma fazenda quitada, não devo. (...) Benção assim, sem medida (Depoimento 2).

Eu passei fome com meus cinco filhos, passei muita necessidade antes de entrar para os 318. Eu saí das dívidas, do SPC, tenho meu nome limpo, ganhei uma causa na justiça. Ganhei três terrenos em São Paulo (...), já comprei dois carros, tenho casa própria, duas lojas de esquina, quitadas, compradas à vista (Depoimento 3).

\section{Considerações finais}

A sociedade brasileira é conhecida por sua pluralidade religiosa que permite com que as pessoas busquem novas formas de experimentações religiosas, através de escolhas. Com a secularização do catolicismo, diversas denominações religiosas expandiram suas fronteiras, surgindo os movimentos neopentecostais como a Igreja Universal do Reino de Deus.

Dentro desse cenário, a questão da midiatização da religião apresenta-se como um fenômeno não apenas do campo religioso, mas sim das práticas sociais, pois a sociedade contemporânea está cada vez mais se autopercebendo a partir dos processos midiáticos, ou seja, é um novo modo de ser no mundo. Dessa forma, a igreja se adapta às lógicas do funcionamento do campo midiático para atingir a população.

Em vista disso, observa-se o crescimento da IURD em meio a uma situação pela qual a população brasileira enfrenta dificuldades financeiras. Apesar das críticas sofridas pela IURD, ela consegue atrair cada vez mais adeptos, através dos seus diversos meios de comunicação, em especial pela televisão, com a Rede Record.

Com o programa «A hora dos empresários», o discurso dos pastores consegue atingir e atrair a camada mais sofrida da sociedade: as pessoas com dívidas, os empresários falidos, os desempregados etc. A estratégia de mostrar os relatos e depoimentos de pessoas que venceram na vida estimula qualquer indivíduo, não importa a religião, a superar as dificuldades e conquistar bens materiais.

A "Nação dos 318 " é uma forte estratégia de captura, pois em nenhuma outra igreja o fiel vai encontrar tantas pessoas orando por ele, só no templo existem 318 pessoas que formam uma sociedade da fé. A IURD também 
oferece diversos horários para o telespectador, que varia desde as $7 \mathrm{~h}$ da manhã até as $22 \mathrm{~h}$, portanto não há desculpas para não buscar a "cura".

Através do programa, os telespectadores compartilham da mesma situação e buscam uma solução que só pode ser resolvida no templo, pois é lá que está o segredo do sucesso financeiro. Nesse sentido, é fundamental a figura do pastor-apresentador na condução do programa, evocando passagens bíblicas e convocando os telespectadores "desesperados" a dirigirem-se à igreja, como pretexto para a evangelização e o pagamento do dízimo para a manutenção do templo.

\section{Bibliografia:}

BAUMAN, Zygmunt. Modernidade líquida. Rio de Janeiro: Jorge Zahar, 2001.

BOURDIEU, Pierre. O poder simbólico. Rio de Janeiro: Bertrand Brasil, 1989.

ESTEVES, João Pissara. A ética da comunicação e os media modernos: legitimidade e poder nas sociedades complexas. Lisboa: Fundação Calouste Gulbenkian, 1998.

FAUSTO NETO, Antonio. "A religião do contato: estratégias discursivas dos novos templos midiáticos”. Em Questão. vol. 10, n 1, janeiro-junho de 2004. Disponível em:

www6.ufrgs.br/emquestao/pdf_2004_v10_n1/EmQuestaoV10_N1_2004_art10. Acesso em: 08/09/2008.

. "Fragmentos de uma 'analítica' da midiatização". Revista Matrizes. São Paulo: ECA/USP, ano 1, $\overline{n^{\circ} 1,2007}$, pp. 89-105. Disponível em: http://www.usp.br/matrizes/img/02/Dossie5_fau.pdf. Acesso em: $13 / 07 / 2008$.

GOMES, Pedro Gilberto. A filosofia e a ética da comunicação na midiatização da sociedade. São Leopoldo: Unisinos, 2006.

RODRIGUES, Adriano Duarte. "Experiência, modernidade e campo dos media". Biblioteca On Line de Ciências da Comunicação. Portugal, 1999. Disponível em: www.bocc.ubi.pt/pag/rodrigues-adrianoexpcampmedia.pdf. Acesso em: 12/07/2008.

SODRÉ, Muniz. "Eticidade, campo comunicacional e midiatização". In: MORAES, Denis. Sociedade Midiatizada. Rio de Janeiro: Mauad, 2006.

VERÓN, Eliseo. "Esquema para el análisis de la mediatización”. Revista Diálogos de la Comunicación. Lima, Felafacs, n 48, 1997.

. "Televisão e política: história da televisão e campanhas presidenciais". In: FAUSTO NETO, A.;

RUBIM, A. A. C. e VERÓN, Eliseo (orgs.). Lula Presidente: Televisão e política na campanha eleitoral. São Paulo, Hacker; São Leopoldo: Unisinos, 2003, pp.15-42. 


\section{Notas:}

Este artigo faz parte de um projeto mais amplo, intitulado "Mídia e religião: um estudo dos novos dispositivos de contato entre o mundo da fé e o fiel", aprovado pelo Edital Universal 2007.

(1) A Record foi alvo de críticas com a polêmica história do chute na Santa, ocorrida durante um programa de baixa audiência transmitido pela emissora. O episódio foi destaque no «Jornal Nacional» e outros telejornais. O bispo Edir Macedo pediu desculpas, declarando que o ato praticado pelo bispo Sergio Von Hélder, não expressava os pensamentos da Igreja. Macedo também alegou estar sendo vítima de perseguição devido ao crescimento de sua emissora que ameaçava a hegemonia da Rede Globo.

(2) Em outubro de 1998, a Rede Record adquiriu sua primeira unidade móvel totalmente digital: um caminhão com quatro câmeras, um «switcher» (aparelho que muda as imagens das câmeras no ar) e três aparelhos de edição vídeo-tape com«slow-motion» (Fonte: www.rederecord.com.br).

(3) Segundo informa a coluna «Outro Canal, da «Folha de S.Paulo, do dia 16 de maio de 2008. Disponível em: http://www1.folha.uol.com.br/folha/ilustrada/ult90u402526.shtml. Acesso em 19 de maio de 2008.

\section{Mini Currículo :}

Carlos Renan Samuel Sanchotene: Mestrando em Ciências da Comunicação pela Unisinos (bolsista CAPES) e colaborador do projeto de pesquisa "Mídia e religião: um estudo dos novos dispositivos de contato entre o mundo da fé e o fiel”, financiado pelo CNPQ. E-mail: carlos_sanchotene@yahoo.com.br.

Viviane Borelli: Professora doutora do Centro Universitário Franciscano (Unifra), Santa Maria, RS. Doutora em Comunicação Social. Programa de Pós-Graduação em Ciências da Comunicação (UNISINOS). Pesquisadora do CNPQ, coordenadora do projeto de pesquisa "Mídia e religião: um estudo dos novos dispositivos de contato entre o mundo da fé e o fiel”. E-mail: viviborelli@unifra.br. 